\title{
An ecological approach of Autism Spectrum Disorders
}

\section{Mihai PREDESCU`, Loredana AL GHAZI, Ioana DARJAN}

\begin{abstract}
Autism Spectrum Disorder (ASD) is one of the most researched topics in the last decades. The research led to a better understanding of the field and raised the number of children properly diagnosed. But also, the ASD became a social topic because it affects both families and society as a whole. In this paper, we propose an innovative ecological approach of ASD, based on a holistic approach of it. We recognize the fact that sectorial approaches, such as intervention in school, or family therapy are not sufficient to overcome the ASD. Instead, we propose an ecological model, in which the assessment and interventions are made at individual, family, school and societal level in order to structure a support network for the child and family.
\end{abstract}

Keywords: ASD; ecological approach.

\section{Introduction}

Autism is a pervasive disorder. The pervasiveness of it means that every aspect of the child's life is shaped by specific patterns of thinking and behaviors. Until we fully understand them, it is difficult to assess them in qualitative terms, but they are clearly inappropriate or inefficient in social life. The pervasiveness of ASD is affecting not only the child but also the family and all its social networks (Karst \& van Hecke, 2012). Most of the families report a high level of stress and burnout raising a child with ASD (Hayes \& Watson, 2013; Vogan et al., 2014), due to the continuous struggle to respond both to children and to social demands (Karst \& van Hecke, 2012).

\footnotetext{
- Associate professor PhD, West University of Timisoara, Romania, University Clinic for Therapies and Psycho-pedagogic Counselling mihai.predescu@e-uvt.ro

- Lecturer PhD, West University of Timisoara, Romania, University Clinic for Therapies and Psychopedagogic Counselling loredana.al@e-uvt.ro

- Lecturer PhD, West University of Timisoara, Romania, University Clinic for Therapies and Psychopedagogic Counselling ioana.darjan@e-uvt.ro
} 
In this context, it is useful to embed any theoretical approach and practical intervention in an ecological context. Using a theoretical circumplex model (Olson, 2011; Posner, Russel \& Peterson, 2005), that has the child in the center; we could define different systems surrounding the children with ASD, from the closest to the more general and comprehensive system. Similarly, any intervention could be assessed according to its depth and focus or to the systems involved. The individual-focused approaches, those based on individual therapies, are ineffective in solving family issues. The more social based interventions, such as state policies, respond to some extent to socialissues, but fail to offer a clear framework for intervention.

In this paper, we will present a theoretical ecological model, based on a systemic approach ofthe ecological development. Then, we propose a five modules intervention that fit this model. The possible benefits and limitations will also be discussed.

\section{The ecological model of ASD}

The ecological perspective of ASD relies on contextualizing autism in the social environment of the child. We are developing this model of explaining ASD inspired by the von Bronfenbrenner's bioecological model of human development (Fig. 1). We will use the photograph metaphor in order to explain it. If we are looking at the social life from the perspective of the child, we will see a photograph of society that is limited to specific perspectives. This is the social niche of the child. Like in any image, the closer the object, the bigger they are, and more important from our perspective.

First of all, we have to take into consideration the child self, needs, traits and life experiences. Those are the main areas that are affected by ASD. This is the internal system, and it is the focus of clinical and psychological perspective of ASD. Most of the assessments are made on specific child's cognitive and social development, and on specific behavioral patterns. Logically, from this perspective, the intervention is made at individual level, attempting to change the child and to facilitate his/her adjustment to external environment. 


\section{Bronfenbrenner's Bioecological Model of Human Development}

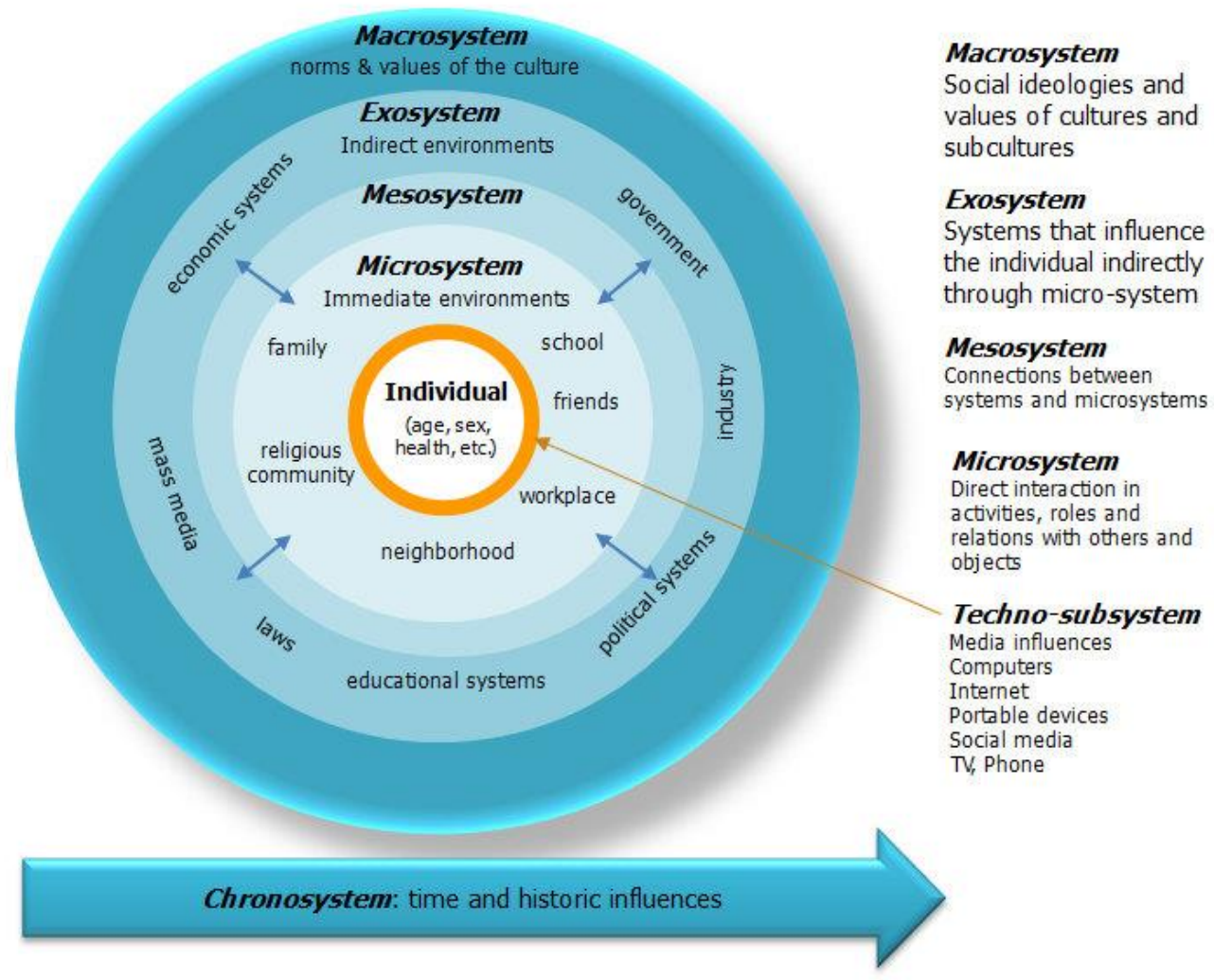

Figure 1: Bioecological Model of Human Development (Bronfenbrenner, 1979)

The closest objects are the family members that are a constant presence in a child's life. The family are part of the microsystem, the immediate environment. The parents are important, not just because they meet the most basic demands of the child, but also because they provide the basic structure of a child's social life. They are the mediators between the child and the larger world. ASD has a powerful impact on family life and dynamic (Hayes \& Watson, 2013). The existence of a child with ASD is forcing families to change in order to include the child's challenging behaviors (Bekhet, Johnson, \& Zauszniewski, 2012). The intervention at this level is mainly family therapy and counseling, parent training and education, aiming to teach and counsel parents to respond properly to child's needs (Preece \& Trajkovski, 2017; Spain et al., 2015).

At a middle distance, the child perceives all the support networks of its family. That includes school, therapists, parents' employers/jobs, networks of friends and community. 
These dimensions are also parts of the microsystem. At this level, including others, are the professionals that are trying to help the child and family. This level is the major support group for the family. Employers are providing financial support; the school is providing educational support, the friends are providing emotional, practical and material supports, and so on. As the main supporting level, we should think about strengthening the social support networks of the child, but it requires a proper coordination.

The mesosystem consists of all the inter-relationships and influences between microsystem and exosystem dimensions.

The exosystem, as an indirect environment, is usually overlooked by the therapists. In child's perspective, this is the background, it is not very clear and outstanding, but it gives colors and makes all image to make sense for our eyes. This exosystem consists on society as a whole and its institution: government, political, economic and educational systems, laws, mass-media and industry. The services and education for the child is regulated by specific policies, the society defines the rights and facilities that are available for the child. Its influence is not so easily to assess, but the effects are great and could be seen in comparative studies across countries.

Every photo is a cut from a larger picture. Even if the photo has a meaning in itself, it is still heavily embedded in a larger picture. This is the macrosystem, which consists of norms and values of the culture and sub-cultures. In social life it includes beliefs, social attitudes, cultural traits and a general understanding of the subject. In the case of autism, the layman theories of it, as a disease, favors clinical approaches of it from a medical perspective. Our discourse about ASD is full of medical terms like diagnosis, therapy, symptoms, et al. On the other hand, that leads to the idea that the children with ASD are sick and needs to be treated and made sane again.

All photos are contextual, environmental cut from a larger picture. The perspective is important, as well as the technique and materials. The last decades witness numerous attempts to depict ASD from multiple perspectives, to take into consideration different voices of those who are taking pictures. Our technique is constantly improving, and we have more data to design intervention programs. Our therapeutically approaches and programs 
are diversifying. We must notice there is a need to build socially agreed perspectives and not just mere individual knowledge.

\section{The Spinner Model}

One of the gadgets that took the world by storm is the fidget spinner. Even if it is a simple toy, it was marketed as a tool for solving fidgeting problem and as a useful instrument for children with autism, due to their fascination for spinning objects and electronic devices (Zubac, I. et al., 2018). We choose to use the spinner as a model for our proposed intervention (Lustrea et al., 2017) (Fig. 2).

The core of the spinner is a simple ball bearing. In our model, this represents the child, which must be the focus of any intervention in ASD. Around the bearing there are lobes (in our case five) in perfect equilibrium. The lobes are spinning around the bearing in continuous movement, constructing an image of a solid object. If one of the lobes is missing, the whole geometry of the spinner is changing. If the lobes are not symmetrical, they do not work together perfectly, and the movement is faulty.

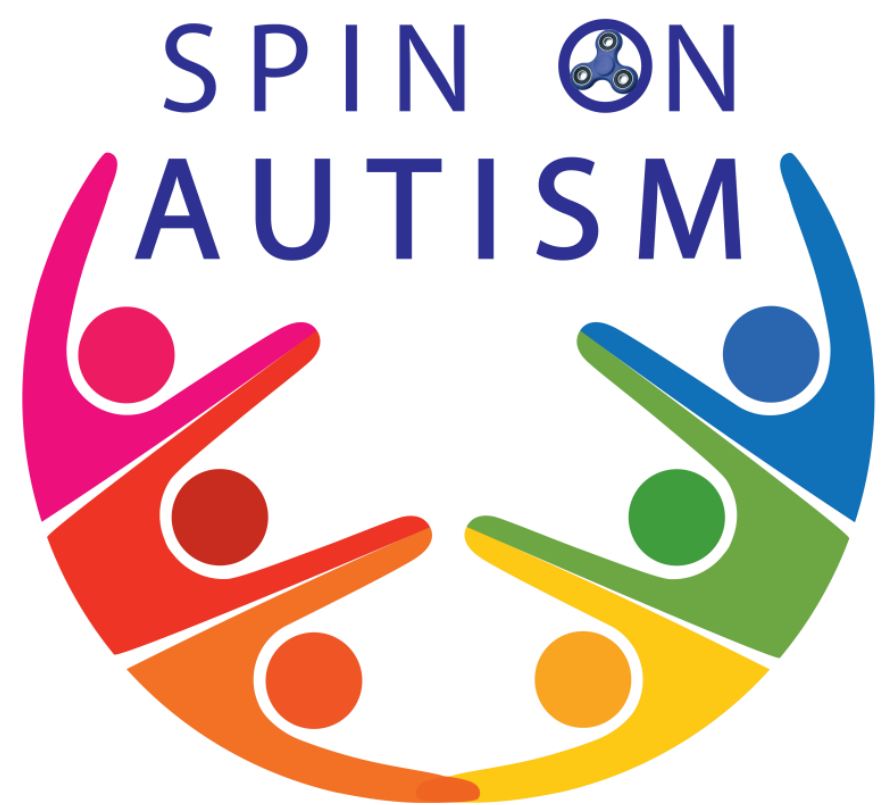

Figure 2: The SPIN Model 
In our spin model, each lobe represents a different challenge for the professionals and responds to a specific ecological need.

The first lobe represents assessment. In our current social approach, the services and supports are available on demands and are based on the assessment of needs. This approach is both socially responsible and meets the criteria of efficient resource allocation. From a clinical point of view, assessment means the diagnosis of the condition (e.g. has or not ASD) and the description of the psychological profile of the children (Yates \& Le Couteur, 2016). However, the assessment is more than that, is a complex evaluation, psychological and social, as well as educational assessment (Ikeda, Hinckson, \& Krägeloh, 2014). The individual assessment offers the basis for a scientific sound intervention (Anagnostou et al., 2014). The assessment must provide a description of the needs for specific services and a prognosis of the intervention outcomes, as well as. The family assessment helps to identify family needs of support, level of adjustment and functioning. School assessment is also useful, especially when inclusion of children is desired.

The second lobe illustrates the intervention. As in the case of the assessment, the intervention crosses ecological levels. Most important interventions were designed for individual treatment of the children. Most of them involve families as well as actions in extensive daily activities. Some interventions are more focused on the interaction between therapist and children. Several interventions are designed for school or educational settings. Most of the interventions are rooted in a scientific approach, are data-driven (based on regular assessment), and based on a managerial approach of the problem-solving situation (case management, SMART objectives, structured planning) (Wood, McLeod, Klebanoff, \& Brookman-Frazee, 2015).

The third lobe is education. One inclusive principle is that every child with disabilities should have the most regular life experience, including socializing experiences with peers, learning in educational setting as well as in other relevant social environment, acquiring competencies for life and for self-development (Lynch \& Irvine, 2009). Education is a musthave experience for children with ASD. Anyway, we have to accept that this experience could be a traumatic one if the school is not truly prepared to meet children's needs in a consistent and coherent manner. The school should develop expertise in educating children 
with ASD (Zappaterra, 2014; Lindsay, Proulx, Scott, \& Thomson, 2014). If we consider curricula as structured educational experiences, then education of children with ASD should be structured in a manner that provides both learning experience and therapeutic activities. As social learning represents an important learning mechanism, it is vital and desirable that the child's whole surrounding environment to be rich in learning experiences and opportunities (Kasari, Locke, Gulsrud, \& Rotheram-Fuller, 2011).

The fourth lobe represents counseling. It is obvious that the entire family has to make a lot of adjustments when it includes a child with ASD. Most of the parents feel helpless and overwhelmed when they first find the diagnosis, and along usual the steps of dealing with loss: denial, anger, bargaining, depression, acceptance (Kubler-Ross \& Kessler, 2005). The entire family requirescounseling and support group to cope with the stress of having a child with ASD (Fiske, Pepa, \& Harris, 2014).

The fifth lobe is advocacy. ASD is a disability that has a powerful effect of children's life. Major social adjustments are needed to facilitate the inclusion of children with ASD in social life. Advocacy is the main tool to promote the children's rights, to facilitate school and social inclusion and to guarantee access to services. Advocacy is build up by, support networks, NGOs, parents alliances, teachers and direct beneficiaries associations (“Advocacy | Autism Speaks," n.d.).

\section{How the model works}

A model becomes useful if it provides a better understanding of the reality and if it has a practical utility. Our model has two dimensions. One is the number and type of environments. On these dimensions, we could talk about interventions that are focusing at a single level (individual, micro-level, mezzo level, exo-level or macro-level). The second dimension is the type of intervention (lobes from the spinner model), namely assessment, therapy, counseling, education, and advocacy.

Using the two dimensions' model, we could describe any action in terms of action and level of the action. Also, when we design an intervention, we could use the model to select the most appropriate target. Using the two dimensions' model, we could draw a chart, describing a typology of interventions (Fig. 3). 


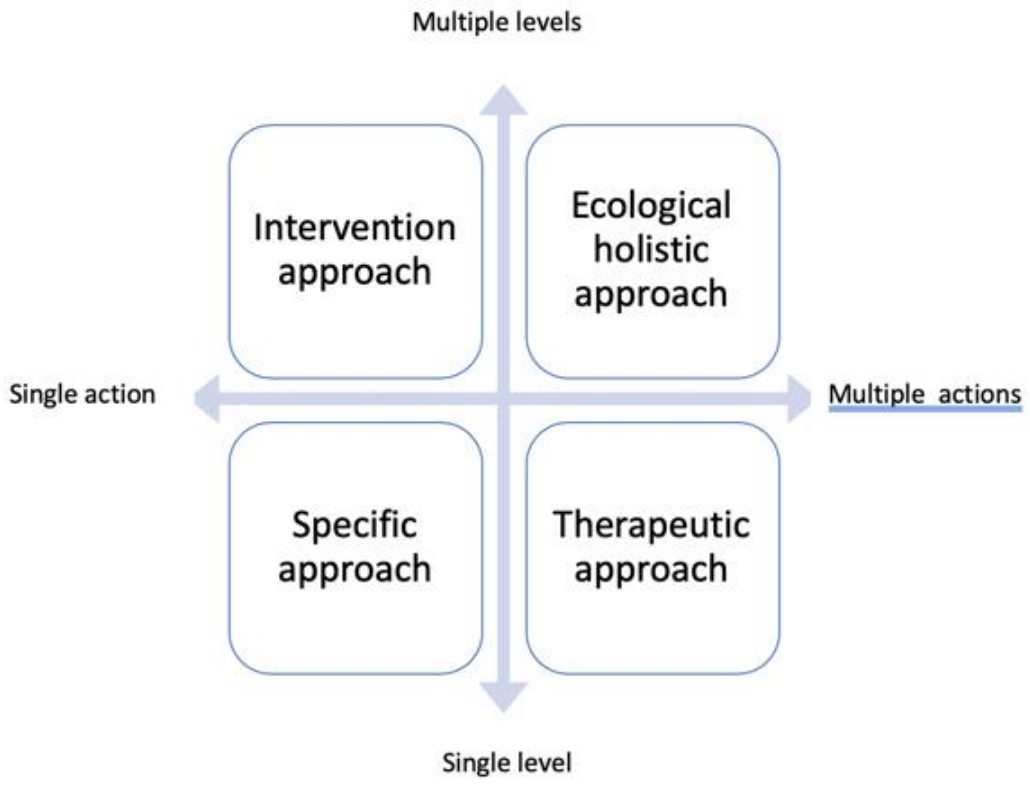

Figure 3. The typology of interventions

According to the two dimensions model, we assign any intervention in one of the four categories. The first type of interventions is based on a specific approach. This type of interventions is locked at a single level and comprises only one type of action. For example, counseling of parents, or a communication therapy for the child with ASD, are specific interventions.

The second type is what we called an intervention approach. This type of intervention is broader regarding the reached level but are still focusing on a single action. Advocacy measures that are targeting families, schools and public institutions are an example of this type of intervention.

The third model is a traditional therapeutic approach. It consists on different coordinated actions, concentrated at a single level. Case-based management is an example of this kind of approach.

Finally, a holistic ecological approach aims to coordinate multiple actions that are reaching different levels from the child's environment. Such measures are more difficult to implement, but they are by far more relevant in terms of results and impact. 
All types of interventions have their logic and usefulness according to a specific context. Regarding effects, the more comprehensive is the approach, the better are the chances to have a sustainable impact and change. On the other hand, the more focused the intervention, the better are the chances to solve specific problems. In other words, the selection of a specific type of intervention is a function of the context and the purpose.

A more comprehensive representation of the model is to have represented different levels of interventions and a cylinder of actions (Fig. 4).

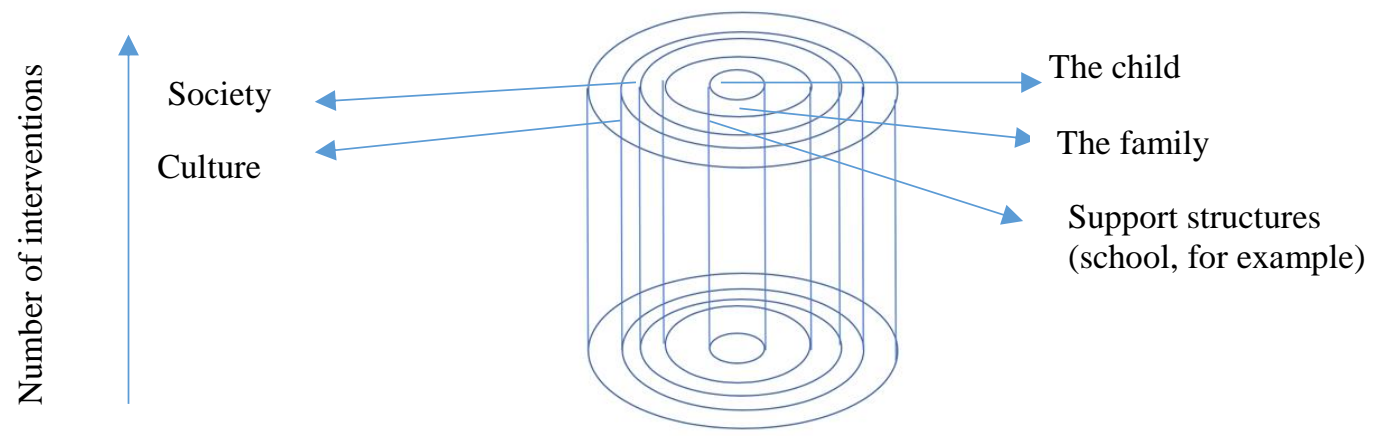

Figure 4. The circumplex model of intervention

The core of the model, and the reason of intervention is the child with ASD. Developing intervention strictly focused on child's needs could be effective but is incomplete. Developing more inclusive approaches should always involve the central core of the model. In other words, any family intervention should also involve the children, and any schoolbased intervention should also involve the family and its child.

\section{Advantages and limits of the model}

We intended to provide an easy model of ASD intervention. What makes a good model is a debatable issue because the opinions differgreatly from one discipline to another. However, there are some general agreed characteristics of any good model.

The model should have a target and should be a schematic representation of it. Our target is intervention in ASD. The model is developedin two dimensions: the level of intervention and the specific actions. Our model illustrates the complexity of ASD intervention in an ecological context. That should be useful in redesigning specific interventions in a more comprehensive approach. As a re-presentation, the model only 
offers the general traits of interventions and leave some other characteristics outside the model. We must keep in mind that a model is not a complete description, not a magic formula. It must offer space for accommodation, individualization and improvement. For example, our model does not take into consideration the agents of intervention.

The model should allow developing new hypothesis about how the target works. A model is useful if it allows us to test the hypothesis and make predictions. In our case, the model allows us to predict that a change at school level is still hindered by cultural norms and values about disability (in general) and ASD (in particular). Another blockage in developing effective school intervention is the social roles ascribed to schools. The model also permits us to predict that school-level interventions are more effective if they would involve a family approach rather than a child-focused approach.

A model should differ from the target and should to be easier to understand. The main reason of developing theoretical models is to reduce the complexity of the reality to an easier to handle the current situation. In other words, the model is not an exact representation of reality. The tension between the need of a model to accurately mirror the reality and, in the same time, the attempt to make it easier to understand by adjusting and explaining it, is not easy to solve. A model too complex would be ineffective, and a model to simplistic would be useless.

Our model is concerned with organizing efficient interventions that are well embedded in the ecological niche of the children with ASD. There are several key-issues that are not solved by our model.

As we said earlier, the issue of the agents of the intervention has not been addressed in our model. The agent could be a professional, a parent, a teacher, a social worker and so on. Another limitation of our model is the temporal dimension of intervention and its interaction with our model. Usually, the more focused interventions are short term. In order to produce social change, there is a need for multiple long-terms interventions.

The resources involved is another issue of the intervention that was not taken yet into consideration in this model. 


\section{Conclusions}

The main motivation for designing a model of ASD intervention resides in our need to develop better interventions for children with ASD. Most of our previous interventions were focused either on the child, on family counseling or on educational inclusion. In each of the interventions, we experience the urge to enlarge the support networks for intervention, for more sustainability and impact of our therapeutic actions.

The ecological approach of intervention in early education is not a new one. The role of all environments and the interaction between those environments are well documented. But, when it came to ASD, most of the approaches fall into a medical paradigm that decontextualizes the child, turning him into a "patient". We felt the need to contextualize the intervention. Also, clinical terms are usually conceptualizedin medical manner, with a direct link between the subject and the method. For example, assessment is usually reduced to child assessment and, sometimes, to child functioning in family or school setting. Butassessment of school readiness for teaching ASD children or the assessment of the job facilities for children with ASD are not so common.

An ideal intervention consists isdiverse actions along multiple environments. Like any such ideal version of intervention, it is not the most feasible and it requires a lot of human, material, and time resources. Anyway, this personalized and contextualized approach is the most honest, complete and efficient for all issues regarding human mental health. And, for sure, it is a desirable one for the ASD, a condition that is not fading, but is a pervasive, stable condition, another small but still perplexing sample of human diversity.

\section{Authorship statement}

The authors of this paper take public responsibility for the content and have had equal contribution in concept development, design, analysis, writing, or revision of the manuscript.

\section{References}

Advocacy | Autism Speaks. (n.d.). Retrieved November 27, 2018, from https://www.autismspeaks.org/advocacy 
Anagnostou, E., Zwaigenbaum, L., Szatmari, P., Fombonne, E., Fernandez, B. A., Woodbury-Smith, M., ... Scherer, S. W. (2014). Autism spectrum disorder: Advances in evidence-based practice. CMAJ, 186 (7), 509-519. https://doi.org/10.1503/cmaj.121756

Bekhet, A. K., Johnson, N. L., \& Zauszniewski, J. A. (2012). Resilience in family members of persons with autism spectrum disorder: A review of the literature. Issues in Mental Health Nursing, 33 (10), 650-656. https://doi.org/10.3109/01612840.2012.671441

Bronfenbrenner, U. (1979). The ecology of human development. 1st ed. Cambridge, Mass.: Harvard University Press.

Fiske, K. E., Pepa, L., \& Harris, S. L. (2014). Supporting parents, siblings, and grandparents of individuals with autism spectrum disorders. Handbook of Autism and Pervasive Developmental Disorders: Assessment, Interventions, and Policy., Volume 2, 4th Ed. https://doi.org/10.1002/9781118911389.hautc40

Hayes, S. A., \& Watson, S. L. (2013). The impact of parenting stress: A meta-analysis of studies comparing the experience of parenting stress in parents of children with and without autism spectrum disorder. Journal of Autism and Developmental Disorders, 43 (3),629-642. https://doi.org/10.1007/s10803-0121604-y

Ikeda, E., Hinckson, E., \& Krägeloh, C. (2014). Assessment of quality of life in children and youth with autism spectrum disorder: a critical review. Quality of Life Research : An International Journal of Quality of Life Aspects of Treatment, Care and Rehabilitation, 23 (4), 1069-1085.https://doi.org/10.1007/s11136013-0591-6

Karst, J. S., \& van Hecke, A. V. (2012). Parent and Family Impact of Autism Spectrum Disorders: A Review and Proposed Model for Intervention Evaluation. Clinical Child and Family Psychology Review, 15 (3), 247277. https://doi.org/10.1007/s10567-012-0119-6

Kasari, C., Locke, J., Gulsrud, A., \& Rotheram-Fuller, E. (2011). Social networks and friendships at school: Comparing children with and without ASD. Journal of Autism and Developmental Disorders, 41 (5), 533544. https://doi.org/10.1007/s10803-010-1076-x

Lindsay, S., Proulx, M., Scott, H., \& Thomson, N. (2014). Exploring teachers' strategies for including children with autism spectrum disorder in mainstream classrooms. International Journal of Inclusive Education, $18(2), 101-122$.

https://doi.org/10.1080/13603116.2012.758320

Lustrea, A.; Al Ghazi, L.; Borca, C. (2017). Innovative academic course on integrative interventions for children with autism spectrum disorders, Journal of Educational Sciences, XVIII Nr. 2(36) 2017, 56-68

Kübler-Ross, E., \& Kessler, D. (2005). On grief and grieving: Finding the meaning of grief through the five stages of loss. New York: Toronto: Scribner.

Lynch, S. L., \& Irvine, A. N. (2009). Inclusive education and best practice for children with autism spectrum disorder: An integrated approach. International Journal of Inclusive Education, 13(8), 845859.https://doi.org/10.1080/13603110802475518

Olson, D. (2011) FACES IV and the Circumplex Model: Validation study. Journal of Marital and Family Therapy, 37(1), 64-80.

Preece, D., \& Trajkovski, V. (2017). Parent Education in Autism Spectrum Disorder -- a Review of the Literature. Croatian Review of Rehabilitation Research / Hrvatska Revija Za Rehabilitacijska Istrazivanja, 53(1), 128-138. https://doi.org/10.31299/hrri.53.1.10

Posner, J., Russell, J., Peterson, B. (2005) The circumplex model of affect: An integrative approach to affective neuroscience, cognitive development, and psychopathology. Development and Psychopathology, 17(3), 715-734.

Spain, D., Sin, J., Paliokosta, E., Furuta, M., Chalder, T., Murphy, D. G., \& Happé, F. G. (2015). Family therapy for autism spectrum disorders. Cochrane Database of Systematic Reviews. In D. Spain (Ed.), Cochrane Database of Systematic Reviews. Chichester, UK: John Wiley \& Sons, Ltd. 
https://doi.org/10.1002/14651858.CD011894

Vogan, V., Lake, J. K., Weiss, J. A., Robinson, S., Tint, A., \& Lunsky, Y. (2014). Factors associated with caregiver burden among parents of individuals with ASD: Differences across intellectual functioning. Family Relations, 63 (4), 554-567. https://doi.org/10.1111/fare.12081

Wood, J. J., McLeod, B. D., Klebanoff, S., \& Brookman-Frazee, L. (2015). Toward the Implementation of Evidence-Based Interventions for Youth With Autism Spectrum Disorders in Schools and Community Agencies. Behavior Therapy, 46 (1), 83-95.https://doi.org/10.1016/j.beth.2014.07.003

Yates, K., \& Le Couteur, A. (2016). Diagnosing autism/autism spectrum disorders. Paediatrics and Child Health (United Kingdom), 26 (12), 513-518. https://doi.org/10.1016/j.paed.2016.08.004

Zappaterra, T. (2014). Autismo e Sindrome di Asperger a scuola. Ricerca educativa e formazione degli insegnanti,Educational Reflective Practices, 2014, 47-63, DOI:10.3280/ERP2014-001003

Zubac, I. et al. (2018). Reaction to robots in social and non-social contexts - comparison of children with autism spectrum disorders and their typical peers,Hrvatska revija za rehabilitacijska istraživanja, 54(2),28-38, https://doi.org/10.31299/hrri.54.2.3 